\title{
Studi Pengembangan Pulau Lumpur Sarinah Kabupaten Sidoarjo Sebagai Geo-Ecotourism
}

\author{
Siti Chamdalah, Hasan Ikhwani, dan Wahyudi \\ Fakultas Teknologi Kelautan, Institut Teknologi Sepuluh Nopember (ITS) \\ Jl. Arief Rahman Hakim, Surabaya 60111 Indonesia \\ e-mail: hikhwani@oe.its.ac.id
}

\begin{abstract}
Abstrak-Daratan dengan total luas 94 hektar di kawasan muara Sungai Porong Kabupaten Sidoarjo yang dibentuk dari endapan buangan lumpur Sidoarjo disebut pulau lumpur buatan atau Pulau Sarinah. Secara administratif Pulau Sarinah masuk dalam wilayah Kecamatan Jabon, Kabupaten Sidoarjo, Provinsi Jawa Timur. Daratan buatan yang dibentuk sejak tahun 2011 ini ditumbuhi oleh tanaman bakau mayoritas jenis Api-api (Avicennia Officinalis). Terdapat pula sebuah kolam pendukung aktivitas penelitian dan kolam tempat pembudidayaan beberapa hewan air seperti udang, kepiting dan bandeng. Rencana pengembangan pulau menjadi kawasan ekowisata yang berkelanjutan mendapatkan beberapa kendala yaitu minimnya sarana prasarana pendukung ekowisata, ketidakjelasan status kawasan dan kepengurusan pulau sehingga pengembangan pulau tidak optimal. Maka dari itu, penelitian dengan metode Analisa Hirarki Proses (AHP) yaitu dengan menyatukan persepsi beberapa pihak terkait (pemerintah daerah dan pusat, masyarakat, BPLS serta akademisi) untuk mencapai rumusan pengembangan pulau berdasarkan prioritas kepentingan. Terdapat lima faktor yang diperhitungkan (lingkungan, ekonomi, sosial, hukum dan infrastruktur) dalam proses analisa dan dibantu dengan pengaplikasian software Expert Choice menunjukkan urutan prioritas pengembangan yang harus dilakukan yakni pengembangan destinasi (30,6\%), pengembangan kelembagaan $(28,3 \%)$, pengembangan pemasaran $(24,8 \%)$ dan pengembangan industri $(16,3 \%)$ dengan nilai rasio inkonsistensi sebesar 0.04 .
\end{abstract}

Kata Kunci- AHP, Ekowisata, Expert Choice, Pulau Buatan

\section{PENDAHULUAN}

$\mathrm{W}$ ILAYAH Kabupaten Sidoarjo merupakan daerah delta yang subur karena berada di antara dua sungai besar pecahan Sungai Brantas yaitu Sungai Mas dan Sungai Porong. Lokasi Kabupaten Sidoarjo dilalui oleh jalan arteri primer Surabaya menuju Malang, Madiun dan Banyuwangi. Pemerintahan Kabupaten Sidoarjo berada di daerah sekitar alun-alun Sidoarjo dan Masjid Agung Sidoarjo yang membawai 18 Kecamatan, 31 Kelurahan dan 322 Desa [1]. Selain itu, Sidoarjo juga terdiri dari beberapa pulau. Hingga kini yang tertera dalam hasil survei BPS Kabupaten Sidoarjo terdapat dua pulau yaitu Pulau Dem dan Pulau Sarinah. Pulau Dem dengan luas 500 Ha yang terletak di antara Sungai Brantas dan Selat Madura. Sedangkan Pulau Sarinah hanya terdiri dari luas $94 \mathrm{Ha}$.

Pulau lumpur buatan yang dikenal dengan nama Sarinah terletak pada jarak sekitar satu sampai satu setengah jam dari Desa Kedungpandan Kecamatan Jabon Kabupaten Sidoarjo. Pulau yang terbentuk dari endapan buangan lumpur Lapindo di muara Sungai Porong ini merupakan objek wisata bahari yang terletak Dusun Tlocor. Dari pusat Kota Sidoarjo Pulau Sarinah berjarak sekitar $21 \mathrm{~km}$.

Kali Porong Kota Sidoarjo merupakan media pembuangan lumpur sampai ke laut. Sehingga pada tahun 2011 Badan Penanggulangan Lumpur Sidoarjo (BPLS) melakukan pengerukan terhadap endapan yang terbentuk di mulut muara Sungai Porong untuk mempertahankan fungsinya. Hasil kerukan tersebut ditimbun pada suatu daerah pembuangan (disposal area) yaitu disamping daratan alami seluas 4.47 hektar. Untuk menjaga agar timbunan endapan lumpur yang

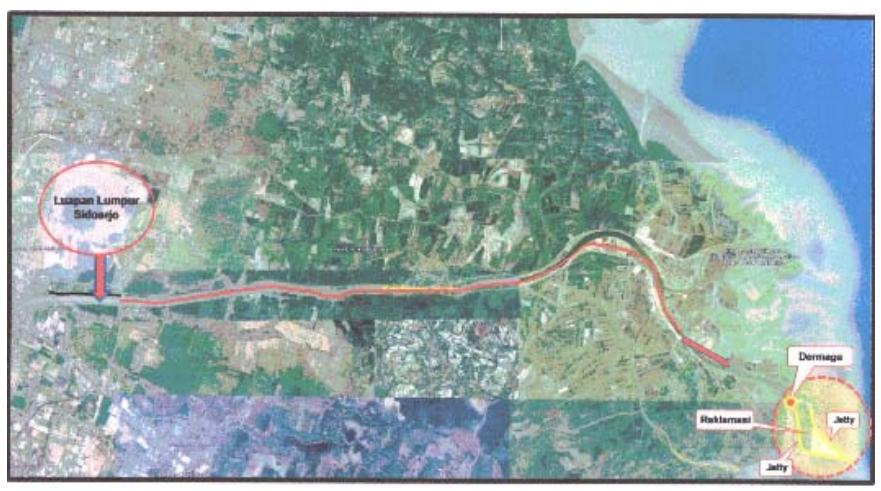

Gambar 1. Jarak Pusat Semburan Lumpur dengan Pulau Sarinah

memiliki total luas sebesar 94 hektar (termasuk di dalamnya wanamina seluas $4.9 \mathrm{Ha}$ ) dapat tetap stabil dan tidak melebar kemana-mana atau menyatu dengan perairan maka perlu adanya konstruksi jetty dengan panjang $3.96 \mathrm{Km}$ [2].

Sayangnya struktur pengelola dan sistem pengelolaan obyek wisata pulau di kecamatan Jabon ini masih sangat terbatas, hanya dapat diakses melalui jalur air dengan menaiki perahu milik warga yang hanya berjumlah dua unit, pada waktu tertentu penjaga pulau yang hanya terdiri dari sebuah keluarga itu pulang ke kampung dan meninggalkan pulau tanpa penghuni, jembatan penyeberangan yang telah dibangun

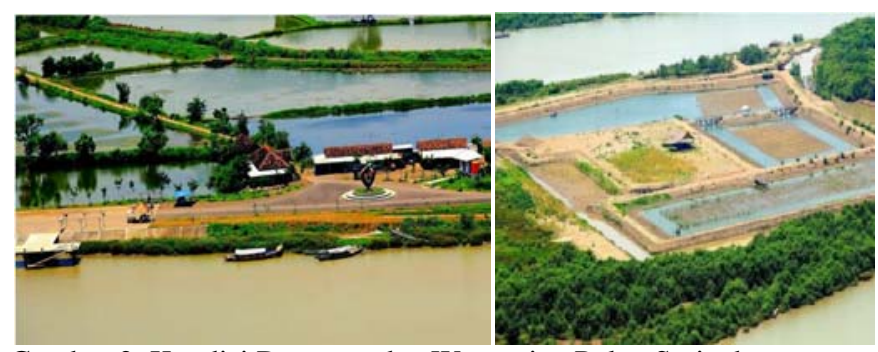

Gambar 2. Kondisi Dermaga dan Wanamina Pulau Sarinah

dengan bahan dasar kayu tidak terlalu kuat dan mulai rapuh, belum ada pemetaan pulau yang jelas, belum ada fasilitas 
penunjang kegiatan wisata yang lengkap, jalan-jalan setapak pun masih sedikit dan juga fasilitas yang telah ada (balai pertemuan dan kamar mandi) masih belum mampu mencukupi kebutuhan pengunjung. Selain itu, masalah utama yang dihadapi adalah ketidakjelasan status kawasan dan pengelola pengembangan pulau. Sehingga selama ini pengunjung yang datang terbatas wisatawan lokal dan kelompok peneliti saja. Oleh karena itu untuk selanjutnya yang perlu dipertimbangkan adalah merumuskan konsep dan melakukan pengembangan yang terpadu serta didukung oleh peran berbagai pihak terkait sehingga mampu mengadakan pengembangan wilayah sebagai unit wisata yang berkelanjutan dan menarik lokal maupun wisatawan manca negara atau dengan kata lain mampu menjadi obyek wisata andalan Kabupaten Sidoarjo bertaraf nasional.

\section{URAIAN PENELITIAN}

\section{A. Tahap Studi Literatur}

Studi literatur dilakukan selama proses pembuatan Tugas Akhir berlangsung. Literatur diperoleh dari buku, internet, jurnal penelitian, dan diktat mata kuliah yang relevan. Studi literatur dilakukan dalam rangka menambah pengetahuan peneliti dalam melakukan penelitian, sehingga penelitian yang dilakukan memiliki dasar teori yang kuat dan bisa dipertanggungjawabkan secara ilmiah. Tema literatur penulis menitikberatkan tentang pengembangan pulau (pesisir) dan konsep ekowisata serta metode AHP.

\section{B. Pembelajaran Masalah}

Studi literatur dan kajian pustaka yang telah dilakukan kemudian diterapkan adanya sebuah masalah pada lokasi penelitian yang kemudian dianalisis untuk menentukan faktorfaktor penyebab serta perumusan solusi dan kebijakan yang sederhana namun melibatkan peran seluruh stakeholder dalam proses realisasi.

\section{Penentuan Tindakan}

Rumusan masalah, solusi dan kebijakan-kebijakan yang telah terkumpul dari seluruh pihak terkait kemudian dianalisa dengan dikaitkan pada beberapa faktor yang mempengaruhinya. Dalam penentuan hasil, penulis berpedoman pada metode Analisa Hirarki Proses. Tahap pertama yaitu menyusun struktur hirarki sesuai berisi tujuan, stakeholder, criteria yang berpengaruh dan alternatif solusi. Membuat instrumen kuesioner yang sesuai dengan hirarki untuk mendapatkan persepsi, seluruh persepsi yang dikumpulkan kemudian dimasukkan dalam program Expert Choice. Proses running diawali dengan perbandingan berpasangan dari tingkat hirarki tertinggi yaitu tujuan penelitian terhadap satu per satu tingkat hirarki kedua yaitu pelaku pengembangan pulau dan selanjutnya hingga level paling bawah yang berisi alternatif solusi. Untuk mengetahui bahwa data yang dimasukkan valid perlu adanya perhatian pada Consistency Ratio dari semua perbandingan berpasangan yang terjadi dengan batas tertentu. Sedangkan untuk mengetahui urutan prioritas elemen yaitu dengan memperhatikan besar rataan nilai eigenvector, semakin besar nilainya maka semakin tinggi tingkat prioritas.

\section{Laporan}

Hasil Analisa Hirarki Proses yang didapatkan kemudian disusun dalam sebuah laporan dengan sederhana dan jelas agar mudah dipahami oleh pembaca sehingga mampu menjadi sumber dan tambahan informasi penting bagi pihak terkait penelitian selanjutnya.

\section{HASIL DAN PEMBAHASAN}

\section{A. Potensi Sumber Daya Alam}

Wilayah Sidoarjo memiliki ekosistem hutan mangrove yang membentang di sepanjang pesisir timur Kabupaten Sidoarjo, mulai dari Kecamatan Waru sampai dengan Jabon. Hutan ini membentuk seperti sebuah sabuk hijau yang terbentang di pesisir sepanjang $27 \mathrm{~km}$ dengan ketebalan bervariasi mulai dari 100-200 meter. Terdapat tidak kurang dari 22 spesies mangrove yang tumbuh di pesisir Kabupaten Sidoarjo dengan 10 spesies termasuk dalam kelompok mangrove sejati (true mangrove) dan sisanya 12 spesies termasuk asosiasi mangrove (associate mangrove) yang dapat tumbuh dengan baik pada substrat dasar berupa lumpur berpasir dan tahan terhadap salinitas serta penggenangan yang tinggi sehingga seringkali menjadi spesies pioneer pada banyak lokasi. Sedangkan jenis mamalia yaitu monyet ekor-panjang (Macaca fascicularis). Mamalia ini muncul hanya untuk mencari makan biasanya saat pohon-pohon Sonneratiaceae (bogem) sedang berbuah. Selain monyet, kawasan mangrove juga sering dihuni oleh kawanan burung air, burung pantai dan biawak. Ekosistem buatan yang terdapat di kawasan Sidoarjo adalah ekosistem tambak (dengan luas mencapai 15.530,41 Ha), ekosistem pertanian dan ekosistem ruang terbuka hijau. Komuditas perikanan utama yang dibudidayakan pada area pertambakan tersebut diantaranya adalah Chanos chanos (bandeng), Panaeus monodon (udang windu), udang vanamei, udang werus, mujair dan sebagainya. Pada tahun 2014, hari hujan maupun curah hujan tidak setinggi tahun 2013. Dari luas lahan sawah $22.830 \mathrm{Ha}$, sepanjang tahun 2014 (3 musim tanam), tanaman padi telah menggunakan area tanam seluas $74,6 \%$, tanaman tebu 13,4\% dan palawija/holtikultura 12,0\% [1]. Dan ruang hijau terbuka didominasi oleh jenis pohon peneduh dan pelindung seperti angsana kembang (Pterocarpus indicus), mahoni (Swietenia mahagoni), asam jawa (tamarindus indicus), trembesi (Samanea saman), randu (Ceiba Pentandra), kamboja (Plumeria spp) dan sebagainya. Lain halnya untuk tanaman yang mengisi RTH pribadi antara lain adalah tanaman hias seperti bugenvil (Bougainvillea spp), puring (Codiaeum variegatum) dan beberapa jenis palem (Arecaceae) dan sikas (Cycadaceae) serta tanaman-tanaman berbunga dan berdaun indah lainnya [3]. 


\section{B. Teknik Pengambilan Sampel}

Kuesioner sebagai instrumen utama penelitian menggunakan teknik pengambilan sampel yang berpedoman pada tujuan penelitian (Purposive Sampling). Jumlah responden didapatkan dari perhitungan menggunakan Persamaan Slovin dimana jumlah populasi (N) sebanyak 169 jiwa (masyarakat sekitar pulau) dengan taraf signifikan $(\alpha)$ sebesar 10\% didapatkan 63 responden.

\section{Analisa Hirarki Proses}

Struktur hirarki pengembangan pulau Sarinah berisi lima level yaitu:

1. Tujuan yang ingin dicapai yaitu pengembangan obyek wisata pulau lumpur buatan (Sarinah) secara optimal dan berkelanjutan.

2. Pelaku atau Stakeholder adalah orang atau lembaga yang berpengaruh dalam pengembangan pulau Sarinah (PEMDA, BPLS, masyarakat dan akademisi).

3. Kriteria menunjukan apasaja yang perlu dipertimbangkan terkait proses pengembangan pulau lumpur Sarinah. Sedangkan sub-kriteria berisi aspek lebih detail seperti tercantum dalam Tabel 1.

4. Alternatif Solusi yaitu rumusan solusi yang diklasifikasikan menjadi pengembangan destinasi, industri, pemasaran dan kelembagaan.

Tabel 1.Kriteria dan Sub-kriteria Pengembangan Pulau Sarinah

\begin{tabular}{ll}
\hline \hline \multicolumn{1}{c}{ KRITERIA } & \multicolumn{1}{c}{ SUB-KRITERIA } \\
\hline Lingkungan & Sedimentasi \\
& Pencemaran \\
& Air Bersih \\
& Ekosistem \\
Ekonomi & Usaha Mikro \\
& Pendapatan Asli Daerah (PAD) \\
Hukum & Perijinan \\
& Peraturan Daerah (PERDA) \\
Sosial & Lapanga Kerja \\
& Perilaku Masyarakat \\
& Budaya dan Kualitas SDM \\
Infrastruktur & Keamanan dan Ketertiban \\
& Pelabuhan/Dermaga \\
& Listrik \\
& Komunikasi \\
& Transportasi \\
& Fasilitas Umum \\
\hline \hline
\end{tabular}

Dilakukan running Expert Choice dengan memasukkan data kuesioner menunjukkan nilai Consistency Ratio(CR) tidak melebihi 0,1 yang berarti bahwa tingkat konsistensi/akurasi data tidak kurang dari $90 \%$ (data penelitian bersifat konsisten). Misalnya dalam gambar 3 nilai eigenvector tertinggi yaitu dimiliki oleh Pemerintah Daerah (0.326), sehingga urutan prioritas pelaku pengembangan pulau Sarinah adalah Pemerintah Daerah (PEMDA), masyarakat, Badan Penanggulangan Lumpur Sidoarjo (BPLS) dan akademisi. Nilai rasio konsistensi (CR) didapatkan dari perbandingan berpasangan seluruh elemen dalam struktur hirarki pengembangan pulau Sarinah Tlocor Kota Sidoarjo.

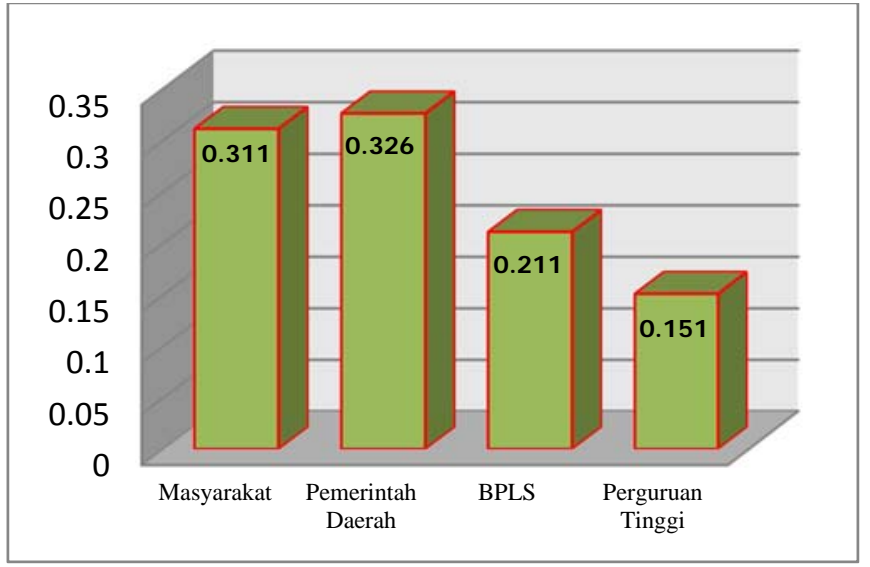

Gambar 3. Nilai Prioritas Pelaku Pengembangan Pulau Sarinah

Hasil Perbandingan Berpasangan Pelaku dan Kriteria Pengembangan

\begin{tabular}{llllll}
\hline \hline \multirow{2}{*}{ NO. } & \multirow{2}{*}{ Kriteria } & \multicolumn{5}{c}{ Vektor Prioritas Pelaku } \\
& & Masyarakat & PEMDA & BPLS & PT \\
\hline 1 & Lingkungan & 0,231 & 0,157 & 0,287 & 0,357 \\
2 & Ekonomi & 0,235 & 0,145 & 0,132 & 0,158 \\
3 & Sosial & 0,212 & 0,130 & 0,126 & 0,245 \\
4 & Hukum & 0,132 & 0,251 & 0,144 & 0,114 \\
5 & Infrastruktur & 0,191 & 0,317 & 0,312 & 0,125 \\
& & 0,04 & 0,02 & 0,02 & 0,02 \\
\hline \hline
\end{tabular}

Hasil akhir analisa Hirarki Proses adalah urutan prioritas solusi pengembangan dengan nilai CR 0,03 sebagai berikut:

1. Pengembangan Destinasi $(0,306$ atau $30,6 \%)$

2. Pengembangan Kelembagaan (0,283 atau 28,3\%)

3. Pengembangan Pemasaran (0,248 atau $24,8 \%)$

4. Pengembangan Industri (0,163 atau $16,3 \%)$

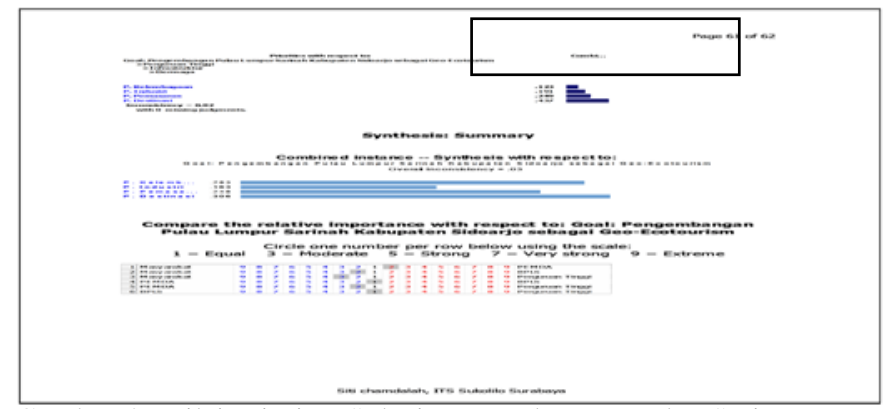

Gambar 4. Nilai Prioritas Solusi Pengembangan Pulau Sarinah

Sedangkan hasil akhir pada struktur hirarki pengembangan pulau Sarinah yang telah disusun pada awal penelitian ditunjukkan pada gambar 4 . 


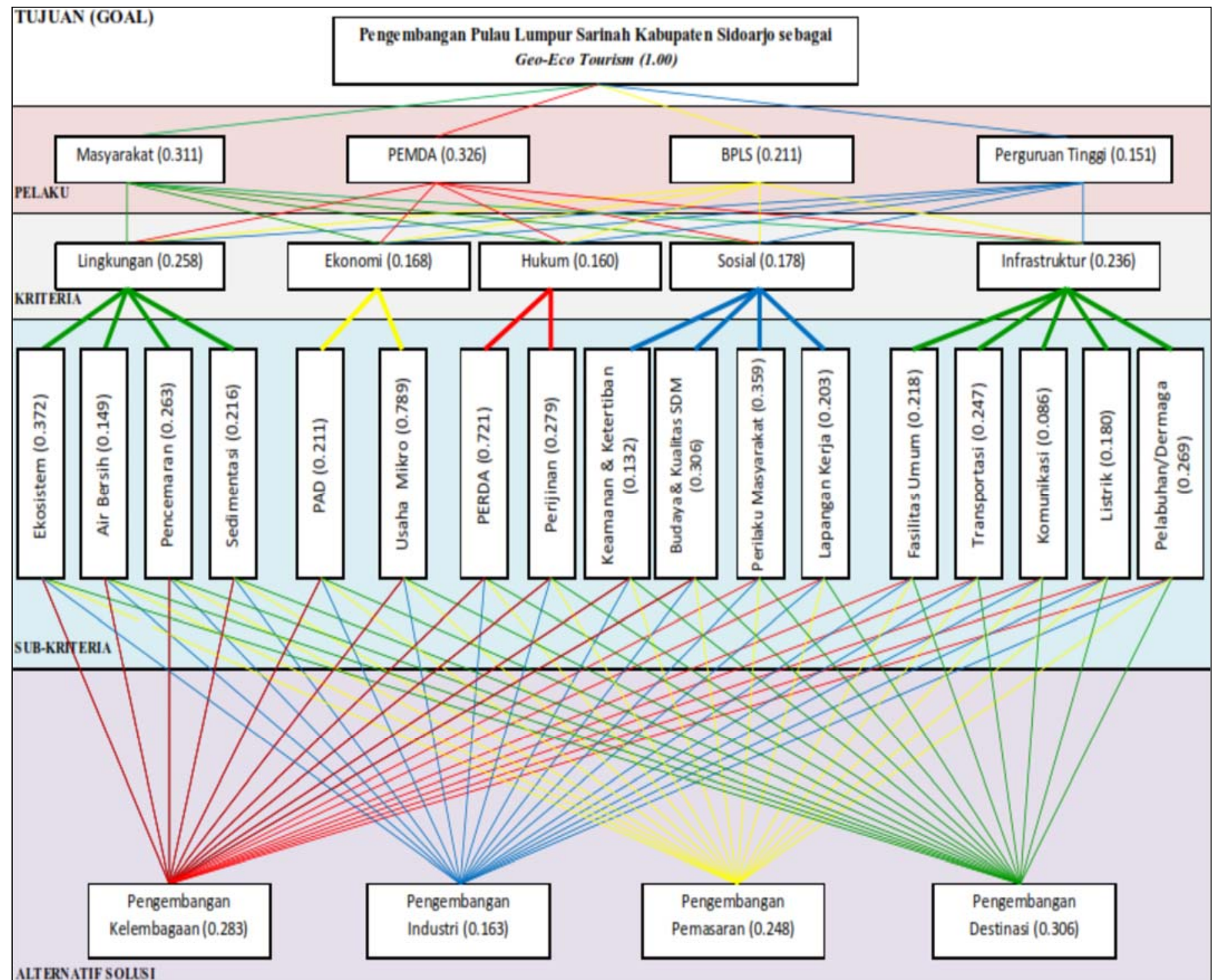

Gambar. 4. Nilai Prioritas Struktur Hirarki Pengembangan Pulau Sarinah Sidoarjo

\section{KESIMPULAN/RINGKASAN}

Berdasarkan hasil analisa dan pembahasan, penulis menarik kesimpulan antara lain:

1. Kondisi eksisting menunjukkan bahwa obyek wisata pulau buatan Sarinah Tlocor memiliki potensi sumber daya yang dapat dikembangkan antara lain keindahan panorama yang didominasi dengan keberagaman jenis tumbuhan mangrove (salah satu jenis paling banyak ditemukan adalah api- api dan bogem), beberapa jenis binatang juga hidup di sekitar pulau seperti monyet ekor panjang dan ikan berjalan, lahan yang sudah menjadi tambak pun sangat luas dengan hasil budidaya utama adalah ikan bandeng, udang dan mujair, serta luasnya hamparan ruang terbuka hijau disekitar jalan menuju dermaga pulau mampu menambah keindahan Sarinah meskipun belum didukung oleh atraksi wisata. Fasilitas dan sarana pendukung wisata terdiri dari lahan parkir, dermaga/pelabuhan, bangunan MCK, warung makanan dan minuman, balai pertemuan, dan tempat ibadah. Terdapat pula sebuah kolam sebagai sarana penelitian bagi akademisi. Aksesibilitas dar i dan menuju ke pulau telah didukung oleh transportasi darat dan laut yang baik meskipun perahu kini masih terbatas.

2. Berdasarkan analisa AHP yaitu dengan menyatukan persepsi beberapa pihak terkait pengelolaan pulau lumpur Sarinah Kabupaten Sidoarjo, urutan prioritas yang dapat dirumuskan adalah sebagai berikut:

a.Prioritas pelaku pengembangan adalah pemerintah daerah sebesar 0,326 atau 32,6\%; kemudian masyarakat dengan nilai prioritas 0.311 atau $31,1 \%$; BPLS dengan nilai prioritas 0,211 atau $21,1 \%$ dan terakhir akademisi perguruan tingi senilai 0,151 atau $15,1 \%$.

b.Faktor yang menjadi prioritas pengembangan menurut persepsi pelaku pengembangan berturut-turut adalah 
faktor lingkungan (25,8\%), infrastruktur (23,6\%), sosial (17,8\%), ekonomi (16,8\%) dan hukum (16\%).

c.Prioritas kebijakan pengembangan pulau lumpur Sarinah Sidoarjo tertinggi adalah pengembangan destinasi dengan nilai sebesar 0,306 (30,6\%), yang kedua pengembangan kelembagaan 0.283 (28,3\%), pengembangan pemasaran 0,248 (24,8\%) dan terakhir pengembangan ind ustri dengan nilai prioritas 0,163 (16,3\%).

\section{UCAPAN TERIMA KASIH}

Penulis mengucapkan terimakasih kepada semua pihak yang telah membantu, memberikan motivasi, semangat dan doa, khususnya Pemerintah Daerah kota Sidoarjo dan warga Tlocor yang telah mendukung pengumpulan data penelitian ini sehingga dapat diselesaikan dengan baik.

\section{DAFTAR PUSTAKA}

[1] Badan Pusat Statistik Kabupaten Sidoarjo. 2015. Sidoarjo Dalam Angka Tahun 2015. Sidoarjo: Badan Pusat Statistik Kabupaten Sidoarjo.

[2] Badan Penanggulangan Lumpur Sidoarjo. 2015. Rencana Pengelolaan Hasil Reklamasi/ Pulau Buatan Di Muara Kali Porong Kabupaten Sidoarjo. Sidoarjo: BAPEL-BPLS

[3] Badan Lingkungan Hidup Kabupaten Sidoarjo. 2015. Kajian Keanekaragaman Hayati Wilayah Pesisir di Kabupaten Sidoarjo. Sidoarjo: PT Geospasia Wahana Jaya. 